\title{
Catalogue of stage-specific transcripts in Ixodes ricinus and their potential functions during the tick life-cycle
}

\author{
Pavlina Vechtova ${ }^{1,2^{*}} \mathbb{D}$, Zoltan Fussy ${ }^{1,3}$, Radim Cegan $^{4}$, Jan Sterba ${ }^{1,2}$, Jan Erhart $^{2}$, Vladimir Benes ${ }^{5}$ \\ and Libor Grubhoffer ${ }^{1,2}$
}

\begin{abstract}
Background: The castor bean tick Ixodes ricinus is an important vector of several clinically important diseases, whose prevalence increases with accelerating global climate changes. Characterization of a tick life-cycle is thus of great importance. However, researchers mainly focus on specific organs of fed life stages, while early development of this tick species is largely neglected.

Methods: In an attempt to better understand the life-cycle of this widespread arthropod parasite, we sequenced the transcriptomes of four life stages (egg, larva, nymph and adult female), including unfed and partially blood-fed individuals. To enable a more reliable identification of transcripts and their comparison in all five transcriptome libraries, we validated an improved-fit set of five I. ricinus-specific reference genes for internal standard normalization of our transcriptomes. Then, we mapped biological functions to transcripts identified in different life stages (clusters) to elucidate life stage-specific processes. Finally, we drew conclusions from the functional enrichment of these clusters specifically assigned to each transcriptome, also in the context of recently published transcriptomic studies in ticks.

Results: We found that reproduction-related transcripts are present in both fed nymphs and fed females, underlining the poorly documented importance of ovaries as moulting regulators in ticks. Additionally, we identified transposase transcripts in tick eggs suggesting elevated transposition during embryogenesis, co-activated with factors driving developmental regulation of gene expression. Our findings also highlight the importance of the regulation of energetic metabolism in tick eggs during embryonic development and glutamate metabolism in nymphs.
\end{abstract}

Conclusions: Our study presents novel insights into stage-specific transcriptomes of I. ricinus and extends the current knowledge of this medically important pathogen, especially in the early phases of its development.

Keywords: Ixodes ricinus, Tick development, Transcriptome assembly, Reference gene validation, Life stage

\section{Background}

The European tick Ixodes ricinus is a common bloodfeeding arthropod transmitting several widespread human pathogens, including the spirochaete Borrelia burgdorferi causing Lyme disease, tick-borne

\footnotetext{
*Correspondence: vechtova@prf.jcu.cz

${ }^{2}$ Biology Centre CAS, Institute of Parasitology, České Budějovice, Czech Republic
}

Full list of author information is available at the end of the article encephalitis virus (TBEV), the causative agent of human encephalitis and meningitis, Anaplasma phagocytophilum, an intracellular alpha-proteobacterium causing granulocytic anaplasmosis, and Rickettsia spp. causing spotted fever syndrome [1-4]. As the natural distribution and activity of $I$. ricinus have been augmenting over past decades, so have the emergence and manifestation of tick-borne diseases. Worldwide, there are about 10,000 cases of tick-borne encephalitis [5] and 85,000 cases of Lyme disease [6], reported annually

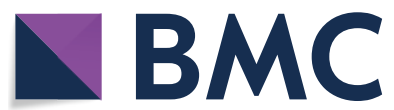

(c) The Author(s) 2020. This article is licensed under a Creative Commons Attribution 4.0 International License, which permits use, sharing, adaptation, distribution and reproduction in any medium or format, as long as you give appropriate credit to the original author(s) and the source, provide a link to the Creative Commons licence, and indicate if changes were made. The images or other third party material in this article are included in the article's Creative Commons licence, unless indicated otherwise in a credit line to the material. If material is not included in the article's Creative Commons licence and your intended use is not permitted by statutory regulation or exceeds the permitted use, you will need to obtain permission directly from the copyright holder. To view a copy of this licence, visit http://creativeco mmons.org/licenses/by/4.0/. The Creative Commons Public Domain Dedication waiver (http://creativecommons.org/publicdomain/ zero/1.0/) applies to the data made available in this article, unless otherwise stated in a credit line to the data. 
and these epidemiological numbers have been raising attention with respect to public health, economy or tourism [7-11]. The life-cycle of arthropod-borne pathogens is tightly bound to the life-cycle of their vectors/ hosts and thus understanding the life-cycle of a vector organism often reveals important aspects of vectorpathogen dynamics including the factors influencing disease transmission to final hosts.

Unlike other haematophagous arthropods, such as mosquitoes or flies, ticks exhibit a complex and rather long life-cycle and they usually require feeding on several host organisms for its completion. Ixodes ticks are able to complete their life-cycle within 3-6 years in wildlife depending on environmental conditions [12]. During its development, the tick hatches from an egg and undergoes metamorphosis and moults to the next active life stages: larva, nymph, or adult [13, 14]. Each moulting is preceded by blood-feeding on the respective host; the selection of host species is perhaps the broadest of all ticks ranging from small mammals, birds, and reptiles in immature stages to large mammals in adult ticks [15]. The time intervals for the completion of each life stage vary and are greatly influenced by many factors such as season, host abundance, selection of host species, or climatic conditions [16]. The feeding itself lasts $3-5$ days in a larval stage, 4-7 days in nymphs, and 7-11 days in adult females [17]. Adult females mate with adult males during feeding on the host to accomplish reproduction. A laid egg batch contains, on average, 2000-2500 eggs [18] but the number of eggs in one batch can reach up to 4000 [19]. The reason for an extraordinarily long life-cycle of I. ricinus is arguably its use of three hosts, in particular when the tick drops off the host after each blood meal and undergoes metamorphosis and moulting off the host [14]. Furthermore, the absence of a host or suboptimal microclimatic conditions (e.g. low temperature) drive the tick to enter a diapause, which can be induced in any life stage and contributes to the extension of its life-cycle [20].

Longevity along with the blood-feeding ectoparasitic life strategy of ticks must have been preceded by many adaptations, differing from those of blood-feeding insects and including features in the regulation of development and metamorphosis that are yet a matter of debate [13].

The efforts to describe factors controlling the development of other arthropod vectors, such as vectors of malaria (Anopheles gambiae) and yellow fever (Aedes aegypti), are mainly focused on the blood-feeding and reveal an upregulation of genes associated with bloodmeal processing, peritrophic matrix formation, egg development, and immunity on the organismal level $[21,22]$ or in salivary glands [23-26], the latter being regarded as a crucial mediator of pathogen transmission to the mammalian host. Several transcriptomic studies were focusing on molecules that might directly influence feeding, such as haem utilization in ticks [27] or arthropod proteases, both being essential factors enabling a haematophagous life strategy [28]. Transcriptional regulation of the entire life-cycle, controlling tick ontogenesis and development has not been fully covered to date and existing research has only focused on a specific organ [29] or a life stage [30].

Due to an increase in its epidemiological importance, I. ricinus has become a species featured in many recent transcriptomic studies, the majority of them focused on the transcription in salivary glands and/or midgut, which are the key organs in the tick-borne pathogens' lifecycle. Studying these organs in response to blood-feeding can be instrumental for the identification of factors that underlie survival and dissemination of pathogens within their vector and their transmission into the final host [24, 31-37]. More specifically, expression analyses using tick haemocytes, the main actors in tick immunity, can unveil the character of the immunity barrier for tick-borne pathogens [29]. Organism-level transcriptomes of feeding stages, on the other hand, can provide a picture of global changes induced by a blood meal [30], hence a more thorough description of factors driving tick developmental processes throughout its life-cycle will be instrumental in understanding the process of hostseeking and blood-feeding as an integral event in tick development.

In this study, we focused on transcripts associated with development, aiming at the presentation of significant new data of the main processes linked to specific life-stages of I. ricinus and functions that are stably expressed. We present a catalogue of transcripts in transcriptome assemblies of several life stages of I. ricinus to provide an outline of transcription important for specific time points of tick development and functions in particular life stages. Our data identified transcripts involved in tick embryonic development thereby providing a source of information for research in tick cell lines, a tick model for in vitro research derived from tick embryonic cells [38]. This represents a significant contribution, which facilitates an initiation and development of methods largely applicable by means of in vitro models such as double-stranded RNA post-transcriptional gene silencing (RNAi) or targeted genome editing using CRISPR/Cas9.

\section{Methods}

\section{Sample preparation and next-generation sequencing}

Both partially fed and unfed life stages of I. ricinus were collected in the tick rearing facility of the Institute of Parasitology, Biology Centre CAS, České Budějovice, Czech Republic; partially fed life stages were fed on 
laboratory guinea pigs obtained at the animal rearing facility therein. The partially fed nymphs were feeding 3-4 days and partially fed females 5-6 days. Under rearing facility conditions, fed females start laying eggs 4 weeks after feeding and the process takes approximately 2 weeks. The eggs were collected immediately after laying and thus represent an early stage of embryogenesis. Larvae were collected after complete hatching of an egg clutch, which usually takes 2-4 weeks. Unfed females were hatching 7-9 weeks after the full engorgement of feeding nymphs. Females were collected after all females had moulted from a batch of nymphs that were feeding simultaneously on laboratory animals. Fed stages were not dissected to remove host blood as haemolymph containing haemocytes and possibly other cells would be lost in the process.

Total RNA was isolated from 3 halves of egg clutches (3 $x \sim 600$ eggs), 3 batches of larvae hatched from 3 halves of egg clutches $(3 \times \sim 600$ individuals), partially fed nymphs $(3 \times 10$ individuals), adult (unfed) females $(3 \times$ 7 individuals $)$ and partially fed females $(3 \times 3$ individuals $)$ of I. ricinus ticks using NucleoSpin RNA II (MachereyNagel, Duren, Germany) according to the manufacturer's instructions. The concentration of RNA was measured using an Implen NanoPhotometer (Implen, Munchen, Germany) and the quality of RNA was determined using a 2100 Bioanalyzer with RNA 6000 Nano kit (Agilent Technologies, Santa Clara, CA, USA). The 3 RNA samples of each life stage were pooled to obtain a single RNA sample per life stage. Each sample is a mixture of three different cohorts of ticks collected in a tick rearing facility in order to cover the genetic variability existing between individuals and to reconstruct the maximum number of transcripts that can be possibly expressed in each life stage. cDNA synthesis and library preparation was carried out using TruSeq DNA Sample Prep kit v2 (PE50 reads) (Illumina, San Diego, CA, USA), followed by sequencing on the HiSeq 2000 platform; both the library preparation and sequencing were performed by the GeneCore facility of the European Molecular Biology Laboratory (EMBL), Heidelberg, Germany.

\section{Transcriptome assembly and annotation}

The PE50 raw reads of all five stages were trimmed off sequencing adapters, short and low-quality reads using Trimmomatic (LEADING:3 TRAILING:3 SLIDINGWINDOW:4:15 MINLEN:36 trimmomatic parameters) [39]. Trimmed reads of all five libraries were used to build a single assembly using Trinity assembler v2.1.1 [40] in order to obtain a highly comprehensive catalogue of complete and high-quality transcripts. Assembly completeness was assessed by mapping the raw reads to the assembly using Bowtie2 v2.3.0 [40] and Samtools flagstat v1.6 [41], followed by BUSCO v3.0.2 search [42] using the catalogue of conserved Arthropoda orthologues in protein mode (database last accessed on 7 July 2017). Contigs showing high similarity to taxonomic groups other than Panarthropoda according to the BlobTools v1.0 pipeline [43] were omitted as possible contaminants.

The contigs of transcriptome assembly were conceptually translated into protein sequences in all six frames. To retrieve annotations, contigs were queried in protein space against TrEMBL, Swiss-Prot, and non-redundant protein database (nr) (downloaded on 30 July 2017) using blastp of BLAST v2.6.0+ with default parameters except for the e-value set to $1 \times 10^{-4}$, returning a maximum of 10 best hits (-max_target_seqs 10). Using a custom Python3 script, the data were integrated with the annotations retrieved by InterProScan v5.36-75.0 [44], which also provided the gene ontology (GO) terms for contigs. Some annotations and GO terms were transferred from the I. ricinus proteome at UniProt, with the criterion for an assignment being $>90 \%$ sequence identity on the protein level.

\section{Validation of assembly completeness}

Assembly completeness and comprehensiveness was assessed by the search of transcripts showing tissuespecific expression. The query protein sequences were downloaded from GenBank (database last accessed on 11 February 2020) (see Table 1 for accession numbers). Blastp of BLAST v2.6.0+ with default parameters was used to search a transcriptome assembly translated into protein sequences in all six frames. The best BLAST hits were collected and their corresponding nucleotide sequences were retrieved from I. ricinus transcriptome assembly. Alignments of query sequences and their best BLAST hits were constructed using MAFFT 1.4.0 [45] integrated within Geneious Prime 2020.0.5 (https://www. geneious.com).

Table 1 Genes used for the validation of assembly completeness. The tissue specificity and supporting references of the listed genes in I. ricinus are also provided

\begin{tabular}{|c|c|c|c|}
\hline Gene & $\begin{array}{l}\text { Accession no. of } \\
\text { nucleotide/protein query } \\
\text { sequence }\end{array}$ & Tissue & Reference \\
\hline IrCD 1 & EF428204.1/ABO26561.1 & Midgut & [54] \\
\hline $\operatorname{lrCD} 2$ & HQ615697.1/ADU03674.1 & Midgut & [54] \\
\hline $\operatorname{lrCD} 3$ & HQ615698.1/ADU03675.1 & Midgut & [54] \\
\hline Iris & AJ269658.2/CAB55818.2 & Salivary glands & {$[55]$} \\
\hline Ixoderin A & AY341424.1/AAQ93650.1 & $\begin{array}{l}\text { Haemocytes, } \\
\text { salivary glands, } \\
\text { midgut }\end{array}$ & {$[56]$} \\
\hline Ixoderin B & AY643518.3/AAV41827.2 & Salivary glands & {$[56]$} \\
\hline
\end{tabular}




\section{Reference genes validation}

Three individual batches (biological replicates) of eggs ( $3 \times \sim 600$ individuals), larvae $(3 \times \sim 600$ individuals $)$, nymphs $(3 \times 15$ individuals), partially fed nymphs $(3$ $\times 10$ individuals), females $(3 \times 7$ individuals $)$, and partially fed females $(3 \times 3$ individuals $)$ of $I$. ricinus were collected in the tick rearing facility as above. Partially fed stages were dissected and host blood washed off in Ringer physiological solution according to Glaser [46]. Removal of host blood was important as it can inhibit the PCR reaction; since the expression of reference genes is expected to be at similar levels in all tissues, the absence of haemolymph, in this case, did not affect the results. Ticks were homogenized in a mixer mill MM 400 (Retsch, Haan, Germany) with steel beads in LBS buffer and RNA was isolated using NucleoSpin RNA Plus (Macherey-Nagel) according to the manufacturer's instructions. The concentration of RNA was measured using an Implen NanoPhotometer (Implen). cDNA was synthesized using ProtoScript II First Strand cDNA Synthesis Kit (New England Biolabs, Ipswich, MA, USA). Primers for reference genes were designed according to I. ricinus transcripts showing the highest sequence identity with publicly available sequences of I. scapularis (see Additional file 1: Table S1 for primer sequences) as determined by blastn of BLAST v2.6.0+ with default parameters. $\mathrm{qPCR}$ reactions for the reference gene expression assay in each life stage were prepared using the qPCR $2 \times$ SYBR Master Mix (Top-Bio, Vestec, Czech Republic) with 20 ng of total RNA transcribed to cDNA as an input for each reaction. The qRT-PCR reaction and fluorescence acquisition were performed using the LightCycler 480 Real-Time PCR System cycler (Roche, Basel, Switzerland) and the resulting $\mathrm{Cq}$ values were recorded and retrieved using the LightCycler 480 Software (release 1.5.0 SP4; Roche, Mannheim, Germany). The validation of reference genes was performed using the BestKeeper v.1 Microsoft Excel-based tool [47]. Gene stability ranking is based on the calculation of pairwise variation of candidate reference genes among samples of different life stages and their biological replications as the standard deviation of $\log _{2}$-transformed expression ratios [48].

\section{The comparison of transcriptomes of Ixodes ricinus life stages}

The reads of the common assembly were redistributed among the tick life stages and their read counts were assigned to the transcripts of the individual life stages in order to facilitate identification and annotation of the transcripts and to enable enrichment analysis and visualization. Transcript quantification was not applied as biological triplicates are necessary for statistical support.
Instead, read count data were used for the annotation of the tick transcriptome assemblies and GO enrichment analysis through identification of correct transcripts and their comparison among individual assemblies. The read count estimation was performed using RSEM (RNA-Seq by expectation-maximization) [49] implemented in the Trinity Transcript Quantification pipeline (accessed on 15 October 2019, [39]). The contigs with low mapping counts were removed in order to avoid the presence of chimeric, fragmented, or biologically insignificant transcripts (cpm $=2$ cut-off). BUSCO v3.0.2 search [42] was performed with the $\mathrm{cpm}=2$ filtered dataset and compared with BUSCO search performed with unfiltered transcriptome described in the "Transcriptome assembly and annotation" section. The mapping counts of each transcriptome were cross-sample normalized to the reference gene counts in order to identify transcripts that are present and specific for each transcriptome. The reference gene scaling factor was calculated using 5 normalization methods: TMM (trimmed mean of M-values), TMMwsp (trimmed mean of M-values with singleton pairing), UQ (upper quartile), and RLE (relative log expression) implemented in edgeR v3.12.0 as suggested by [50] and median normalization (MED) implemented in edgeR as described in [51]. The reference genes' read mapping counts were retrieved from the scaled matrices and their geometric means and geometric standard deviations were calculated in order to select the most efficient normalization method.

\section{Contig clustering and enrichment analysis}

The counts of mapped reads in each transcriptome were transformed into a $\log _{2}$-scaled matrix in order to perform an enrichment analysis. Library-specific transcripts were inferred by hierarchical clustering of the Morpheus matrix analysis software (https://software.broadinstitute. org/morpheus/, last accessed on 30 November 2019) using complete linkage and 1-Pearson correlation metrics. Based on the resulting dendrogram, transcripts were assigned to clusters that are represented in one or more transcriptome assemblies; 2-50 clusters were built and a custom Python3 script was used to calculate withincluster read count variability as a sum of squares function of Euclidean distances from respective cluster centroids. The frozen code is available on GitHub (Fussy, Z. (2019), GitHub repository, https:/github.com/morpholino/ PYTHON/blob/master/clustering_metrics_kliste.py). We used the elbow method to find the inflexion point where a minimal number of clusters explains $\sim 90 \%$ of the total variability of the complete read count matrix. The transcripts assigned to each library were then subjected to GO enrichment analysis by goa-tools v0.8.12 [52] with Benjamini/Hochberg false discovery rate correction; the 
GO terms relationship file (go-basic.obo) from geneontology.org was last accessed on 30 November 2019. A custom Python3 script was used to visualize the enrichment inferred for each transcriptome assembly.

\section{Results}

\section{Transcriptome assembly and annotation}

A total of 430,604,850 paired-end 50-bp reads were obtained by sequencing of all five $I$. ricinus life stages. Trimming and quality filtering yielded 428,514,142 reads (see Additional file 1: Table S1 for details). The transcriptome assembly with Trinity assembler produced 117,583 "Trinity isoforms" and 83,534 "Trinity genes". According to samtools flagstat, the Bowtie 2 mapping rate of all libraries was around $80 \%$, which corresponds to good quality assemblies with little information being lost in unmapped reads (see quality and mapping statistics available in Additional file 2: Table S2).

The RSEM package was used to distribute mapped reads among the five transcriptome assemblies of $\mathrm{I}$. ricinus. Reads with low mapping counts (cpm $=2$ threshold) were removed from the dataset of mapped reads as potentially misassembled or chimaeric. The number of transcripts after this low count filtering dropped from 83,534 to 25,872 , which roughly corresponds to the genome assembly report of the related tick species, $I$. scapularis (23,340 transcripts) [53].

Read mapping counts were calculated in order to identify transcripts that are library-specific, demonstrating the presence or absence of individual transcripts across life stages. This does not necessitate biological replicates compared to statistical analyses required by quantitative RNAseq pipelines.

To enforce a more robust comparison, we scaled the five life-stage libraries to reference transcript counts selected through quantitative reference gene validation (see "Reference gene validation" section below).

Of the five different normalization techniques employed, the RLE method showed the lowest dispersion of reference gene variability among the five assemblies (see Additional file 2: Table S2.). The RLE was used to calculate reference gene normalization factor using mapping counts of five most stable reference genes of intermediate read mapping counts ( $r p s 4, R p L 32, r p l 4$, ferritin and $R p L 13 A$ ), to which the matrix of read mapping counts of the five life stages was scaled.

Of 25,872 contigs of the pooled transcriptome assembly, whose quality and biological relevance was supported by a high number of mapped reads (i.e. contigs passing the $\mathrm{cpm}=2$ threshold), we could find annotation for 13,626 using InterProScan and 9510 of these were assigned GO terms. For some of these, and additional
653 contigs, we could find annotation using BLAST against the $I$. ricinus proteome deposited at UniProt, totalling 14,279 and 11,282 contigs with IPS and/or GO terms, respectively.

A BUSCO search of Arthropoda conserved orthologues within the unfiltered 83,534-contig assembly as an input reported $95.7 \%$ completeness. The assembly of contigs passing the $\mathrm{cpm}=2$ threshold exhibited $95.6 \% \mathrm{com}$ pleteness, which shows that $\mathrm{cpm}=2$ filtering effectively removed low-quality, fragmented, or chimeric contigs introducing false information or carrying an insignificant biological role for the I. ricinus assembly. A detailed BUSCO report is given in Additional file 3: Table S3.

Whole-body transcriptomes may lack mRNAs of lowly expressed genes. This concern motivated us to perform an additional verification of the comprehensiveness of our assembly. Our test was based on an assumption that genes that exhibit tissue-specific expression can be expressed in minute abundances compared to the genes expressed constitutively and organism-wide. Thus, their expression can be undetected if sequencing depth is insufficient or the assembly is of poor quality. We searched publications dealing with $I$. ricinus tissuespecific expression and selected randomly 3 tissue-specific genes and their paralogues. The list of sequences, their accession numbers, and corresponding publications showing their tissue-specific expression profile in I. ricinus are provided in Table 1. In particular, we chose 3 paralogues of cathepsin D (IrCDs) with expression restricted to tick midgut [54], a single sequence of the family of tick serine protease inhibitors (serpins) identified in $I$. ricinus salivary glands (Iris) [55], and two paralogues of fibrinogen-related protein, ixoderin A and ixoderin B showing tissue-specific expression profiles. Expression of ixoderin A was detected in haemocytes, salivary glands and midgut, and transcripts of ixoderin $B$ were found in salivary gland tissue only [56]. Thus, a higher abundance and consequently a higher chance of full recovery of ixoderin A transcript was expected in comparison to ixoderin B. Importantly, our assembly contains sequences corresponding to all six queries (see Additional files 4, 5, 6, 7, 8 and 9 for alignments). We found four isoforms of Iris; all four sequences showed similarly high sequence identity. Of note, for the salivary gland-specific paralogue ixoderin B we also found a transcript, albeit 5 ' truncated. Intriguingly, the ixoderin B query and hit showed only $70 \%$ identity on the amino acid level. However, the best hits within the I. ricinus-specific nr and tsa_nr databases (last accessed 11 Jun 2020) also returned best hits of 75\% (GenBank: ABO09954.1) and 89\% (GenBank: JAB75084.1) identity, respectively, both annotated as ixoderin B5. Nucleotide sequences of these two hits were included in the ixoderin $B$ alignment to support the 
identity of the putative ixoderin B5 sequence from our assembly.

This transcriptome shotgun assembly project has been deposited at DDBJ/EMBL/GenBank under the accession GIDG00000000. The version described in this article is the first version, GIDG01000000.

\section{Reference gene validation}

The selection of candidate reference genes for validation should be performed carefully, ideally based on existing data. Within Acari, only 4 species were analysed for reference gene selection and their validation: Tetranychus urticae [57], Ripicephalus microplus, $R$. appendiculatus [58], and I. scapularis [59]. Our study focused on the identification of transcripts in tick life stages with recommendations from previous publications [58, 59] (Table 2). In total, 13 reference genes were selected for testing; EF1a, ferritin, GAPDH, H3F3A, ppiA, RpL32, RpL13a, rpl4, rps4, sdha, TBP, $T U B B$ and $v$-ATPase. Of these, sdha (succinate dehydrogenase complex flavoprotein subunit A) and $T B P$ (TATA-box binding protein) were excluded from further analysis due to non-specific amplification during qRT-PCR assay optimization (data not shown). The best BLAST hits in our I. ricinus transcriptome assembly, using published I. scapularis references as queries, were used for primer design. These sequences were manually annotated and uploaded to GenBank. The list of $I$. ricinus reference genes used in reference gene validation assay, their accession numbers, and their respective $I$. scapularis queries with references are given in Table 2.
The quantification of $I$. ricinus candidate reference gene expression was performed using qRT-PCR assay. The expression levels of reference genes and their variation in each life stage are given in Fig. 1a and b, respectively. The $\mathrm{Cq}$ values of each reference gene for each life stage and their biological replicates were integrated in BestKeeper v.1 [47]. The list of reference genes and their pairwise correlation coefficients $(r)$ are listed in Table 3. All of the genes showed a strong positive correlation $(r)$ ranging between $0.85-0.99$. Moreover, the first eight genes in Table 3 showed a very strong positive correlation with an $r$-value above 0.9 .

The pairwise correlation coefficient of all eleven tested reference genes indicates a high positive correlation. For normalization, we selected only the most stable reference genes as recommended previously [ 48 , 60-62].

Furthermore, we excluded EF1a gene from the calculation of HK factor for being a highly abundant transcript $(8-12 \mathrm{~K} \mathrm{cpm})$ (data not shown). Medium to highly abundant transcripts are more suitable reference genes due to their clear and reliable detection in every sample [63], whereas highly abundant transcripts tend to express less stably and thus their selection as reference genes should be made with precaution [64].

\section{Identification of transcripts specific for Ixodes ricinus life stages and Gene Ontology enrichment analysis}

A Pearson correlation matrix assigning the transcripts to one or more of the transcriptome datasets was constructed. Of 25,872 transcripts, 10,266 were identified as life stage-specific. The remaining transcripts, identified in all assemblies, were classified as "housekeeping genes",

Table 2 Genes used in reference gene validation assay. The genes were selected based on validation in the referenced studies

\begin{tabular}{lllll}
\hline Gene & Annotation & Reference & Query sequence & $\begin{array}{c}\text { I.ricinus } \\
\text { homologue } \\
\text { sequence }\end{array}$ \\
\hline EF1a & Elongation factor 1a & {$[57,58]$} & GU074814.1 & MN728895 \\
ferritin & Ferritin (somatic) & {$[112]$} & AY277906.1 & MN728896 \\
GAPDH & Glyceraldehyde 3-phosphate dehydrogenase & {$[57-59]$} & XM_002434302.1 & MN728904 \\
H3F3A & H3 histone family 3A & {$[58]$} & XM_002399526.1 & MN728905 \\
RpL13A & Ribosomal protein L13A & {$[59]$} & XM_002436237.1 & MN728901 \\
ppiA & Cyclophilin-type peptidylprolyl cis-trans isomerase A & {$[58]$} & XM_002407873.1 & MN728903 \\
RpL32 & Ribosomal protein L32 & {$[57]$} & XM_002399465.1 & MN728898 \\
rpl4 & Ribosomal protein L4 & {$[58]$} & XM_002402278.1 & MN728900 \\
rps4 & Ribosomal protein S4 & {$[59]$} & DQ066214.1 & MN728897 \\
SAha & Succinate dehydrogenase complex subunit A & {$[57]$} & XM_002408156.1 & MN879329 \\
TBP & TATA-box binding protein & {$[58,59]$} & XM_002402081.1 & MN879330 \\
TUBB & B-tubulin & {$[57,58]$} & GQ411364 & MN728899 \\
v-ATPase & Vacuolar-type H[+]-ATPase & {$[57]$} & XM_002413524.1 & MN728902 \\
\hline
\end{tabular}



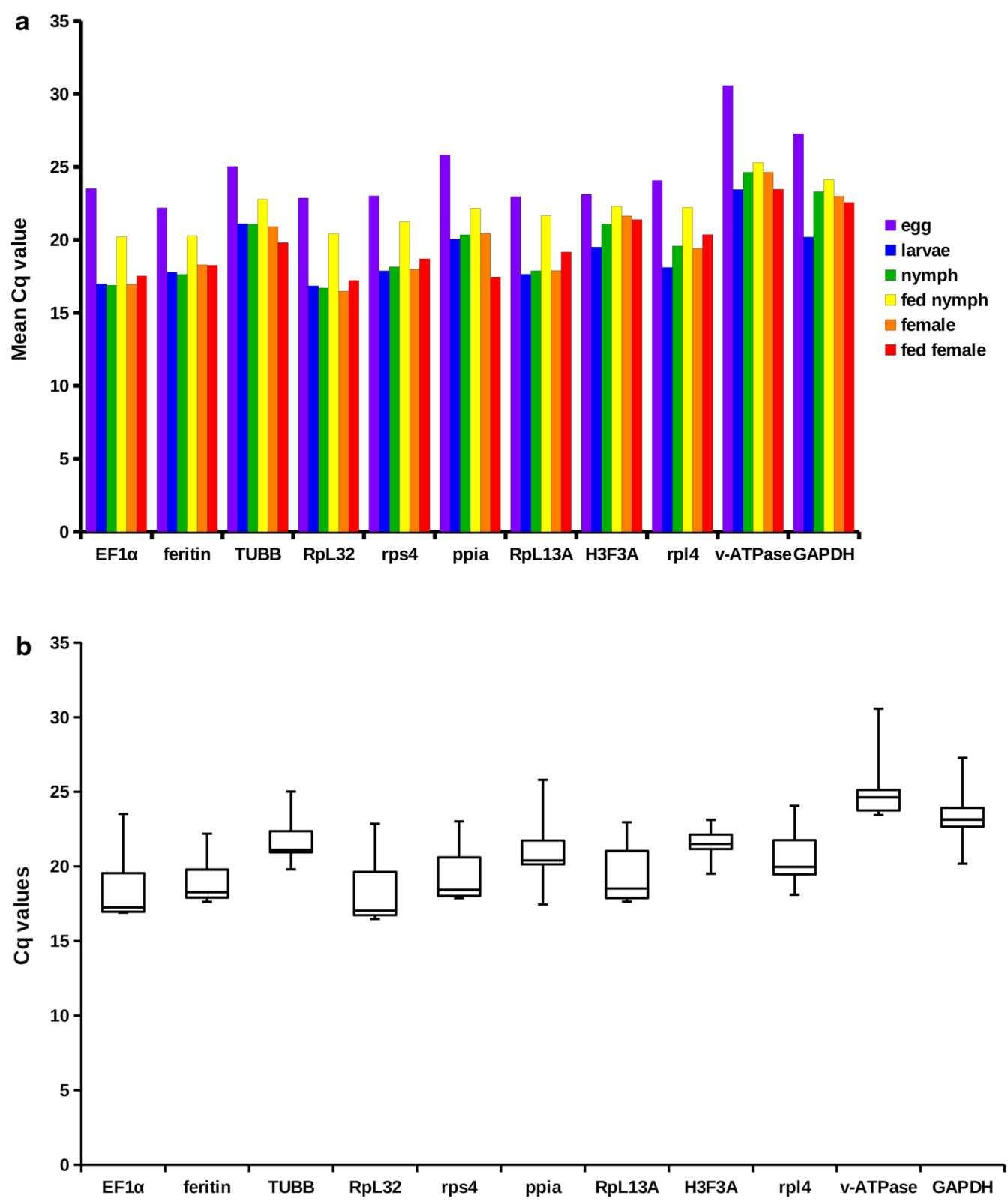

Fig. 1 Reference gene expression levels and stability in different life stages. a Comparison of abundances of reference gene transcripts in six I. ricinus life stages. Each bar represents the geometric mean of Cq values calculated from biological triplicate. $\mathbf{b}$ Transcript abundance variation of each reference gene calculated for six I. ricinus life stages. Individual box plot elements represent the following variables: line, median; boxes, upper and lower quartile; whiskers, range of the dataset

important throughout tick life stages. These transcripts were removed from further analysis as developmentally non-specific (see "HK_transcripts" column in Additional file 10: Table S4). Additionally, transcripts supported with very low read mapping counts (counts per million (cpm) $<2$ ) as by Pearson correlation analysis, were removed from individual libraries prior to the identification of stage-specific transcripts. Numbers of library-specific, as well as housekeeping transcripts upon low read mapping count filtering, are presented in Fig. 2. Note the high number of transcripts present in transcriptomes of both feeding stages and of the egg transcriptome assembly. Transcripts in each stage-specific library were organized according to the number of mapped reads in descending order (Additional file 10: Table S4) and five of the transcripts that were assigned the most reads in each library (Top 5 transcripts) were selected for a detailed annotation and characterisation (Table 3). The presence of these 
Table 3 Genes used in reference gene validation assay. Genes are ordered according to their pairwise correlation coefficient $(r)$ in descending order

\begin{tabular}{llll}
\hline Rank & Gene & $\begin{array}{l}\text { Pairwise correlation } \\
\text { coefficient }(r)\end{array}$ & $P$-value \\
\hline 1 & rps4 & 0.98500 & 0.00100 \\
2 & RpL32 & 0.98333 & 0.00100 \\
3 & EF1a & 0.98333 & 0.00105 \\
4 & ferritin & 0.96467 & 0.00233 \\
5 & rpl4 & 0.95067 & 0.00447 \\
6 & RpL13A & 0.94867 & 0.00523 \\
7 & V-ATPase & 0.94133 & 0.00667 \\
8 & TUBB & 0.93400 & 0.00939 \\
9 & ppiA & 0.89333 & 0.01930 \\
10 & GAPDH & 0.86467 & 0.03381 \\
11 & H3F3A & 0.85867 & 0.04036 \\
\hline
\end{tabular}

transcripts in each life stage is illustrated in Fig. 3. It is evident that transcripts present in fed nymphs are specific for feeding stages and thus can be also found in fed females. Similarly, transcripts identified in unfed females are also detectable in the transcriptome of unfed larval stages. The Top 5 transcripts in I. ricinus eggs, on the other hand, seem to be only present in the egg transcriptome as evident from the heatmap colour intensity in the remaining four libraries.

For the purposes of GO enrichment analysis and annotation, the matrix of read mapping counts of only the stage-specific transcripts was constructed and subjected to hierarchical clustering using complete linkage and 1-Pearson correlation metrics. The resulting dendrogram was cut to 2-50 clusters and their internal variability was calculated (see Methods). As per the elbow method, 10 clusters were the optimal number that accounted most efficiently for the total variability within the matrix (90.33\% explained). Figure 4a presents the graphical illustration of the selected clusters of transcripts and shows their affiliation to particular stage-specific transcriptomes. Gene Ontology enrichment was determined for all transcript clusters, including an additional cluster of transcripts identified as "housekeeping genes", which were removed prior clustering, and visualized as a categorized bubble plot (Fig. 4b). Of 10,266 stage-specific transcripts, 3839 were assigned a GO term; altogether, there were 964 unique GO terms, of which 112 are categorized to cellular components, 391 to biological processes, and 451 to molecular function. Transcripts present in all transcriptome assemblies with assignable GO terms $(n=7,443)$ were added for comparison (see cluster 11 of Fig. 4b). Figure $4 \mathrm{~b}$ presents a detailed visualization of the enrichment of each GO term per stage and cluster.

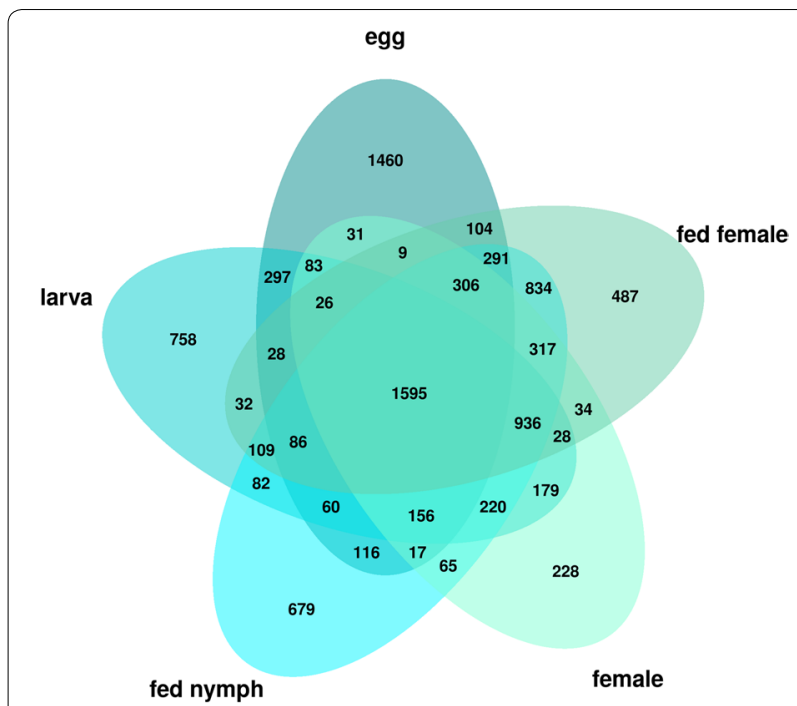

Fig. 2 Graphical illustration of transcripts that are present in different transcriptome libraries. The diagram also shows the number of

"housekeeping transcripts" present in all transcriptomes in the middle intersections. The numbers in the outer intersections show transcripts that are common for more but not all libraries

\section{GO enrichment of transcript clusters in egg and larva life stages}

Clusters 1-4 contain transcripts that were enriched only in egg and larva libraries. In particular, clusters 1 and 2 involve transcripts specific for egg development. Cluster 1 contained transcripts that are almost exclusively enriched in term GO:0030182 which entails the biological process "neuronal differentiation". Cluster 2 was the most enriched with terms describing processes associated with DNA regulation and processing, possibly involving transposon activity, and with cellular adhesion. Cluster 3 presented transcripts identified in both egg and larva assemblies, enriched with GO terms describing transmembrane signal transduction via ligand-gated ion channels (GO:0005234 and GO:0015276). Transcripts in cluster 4 were identified in larval stage only and the most enriched GO terms in this cluster describe cellular energetic metabolism involving glutamine as a main source of energy (GO:0004356 and GO:0006542) or perhaps glutamatergic neuronal activity, in line with glutamate ion channel enrichment in cluster 3.

The annotation of the Top 5 transcripts in the egg identified the transcript c76180_g1, which is highly homologous to cathepsin-like protease (GenBank: EEC15123.1) that plays a major role in egg yolk degradation and is thus implicated in egg development [65]. Another transcript found in the egg library (c80189_g5) is homologous to a conserved protein (GenBank: A0A147BJ18) containing an extracellular CUB domain (abbreviation derived 

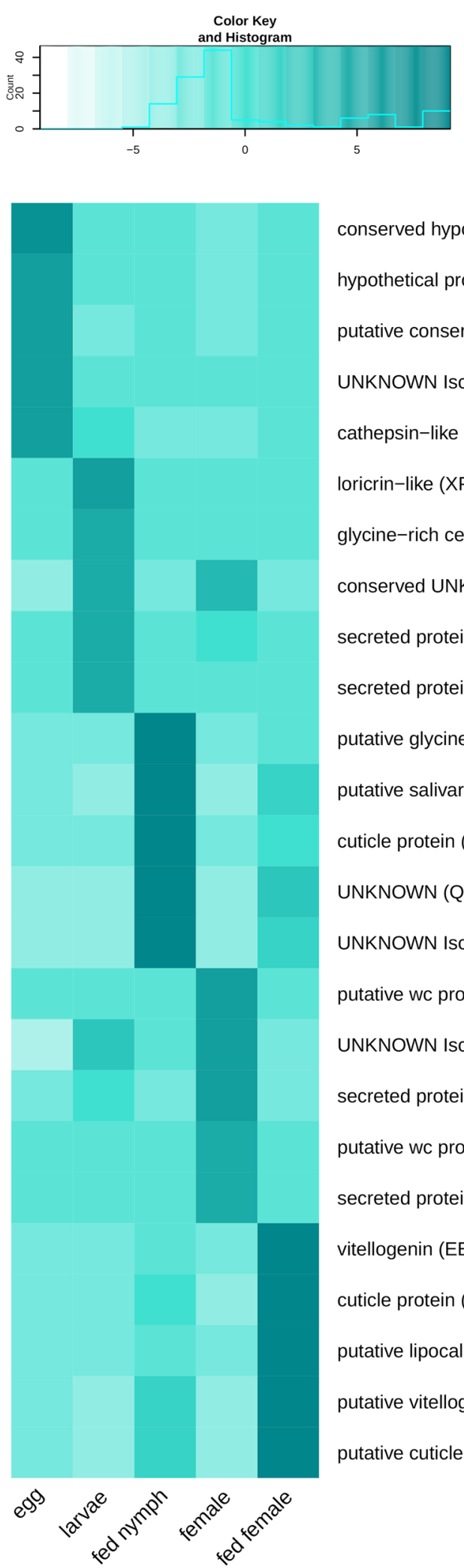

conserved hypothetical protein (EEC13590.1)

hypothetical protein IscW_ISCW003437 (EEC03440.1)

putative conserved protein (CUB domain profile) (A0A147BJ18)

UNKNOWN IscW_ISCW005232 (EEC05138.1)

cathepsin-like protease (EEC15123.1)

loricrin-like (XP_029826130.1)

glycine-rich cell wall structural protein 1.8-like (XP_029826132.1)

conserved UNKNOWN (EEC03354.1)

secreted protein (EEC07345.1)

secreted protein (EEC18324.1)

putative glycine rich protein (JAA67414.1, A0AOK8RAB4)

putative salivary secreted protein of $21.3 \mathrm{kDa}(\mathrm{V} 5 \mathrm{I} 1 \mathrm{~K} 9)$

cuticle protein (EEC02888.1)

UNKNOWN (Q9GP09)

UNKNOWN IscW_ISCW023478 (EEC18809.1)

putative wc protein, secreted protein (A0A0K8RIE7, AAY66590.1)

UNKNOWN IscW_ISCW021550 (EEC14461.1)

secreted protein (EEC18324.1)

putative wc protein, secreted salivary protein (A0A0K8RB73, AAY66559.1)

secreted protein (AAY66620.1, A0A0K8RG69)

vitellogenin (EEC18889.1)

cuticle protein (EEC14155.1)

putative lipocal-1 1 lipocalin (V5I261)

putative vitellogenin 2 (A0A147BKD0)

putative cuticle protein (A0A0K8RN13)

Fig. 3 The presence of Top 5 transcripts in the I. ricinus common assembly used for GO enrichment and annotation. The heatmap is clustered according to transcripts read mapping counts in cpm in each life stage in descending order. Transcript descriptions are supplied with an accession number of the best BLAST hit in brackets 


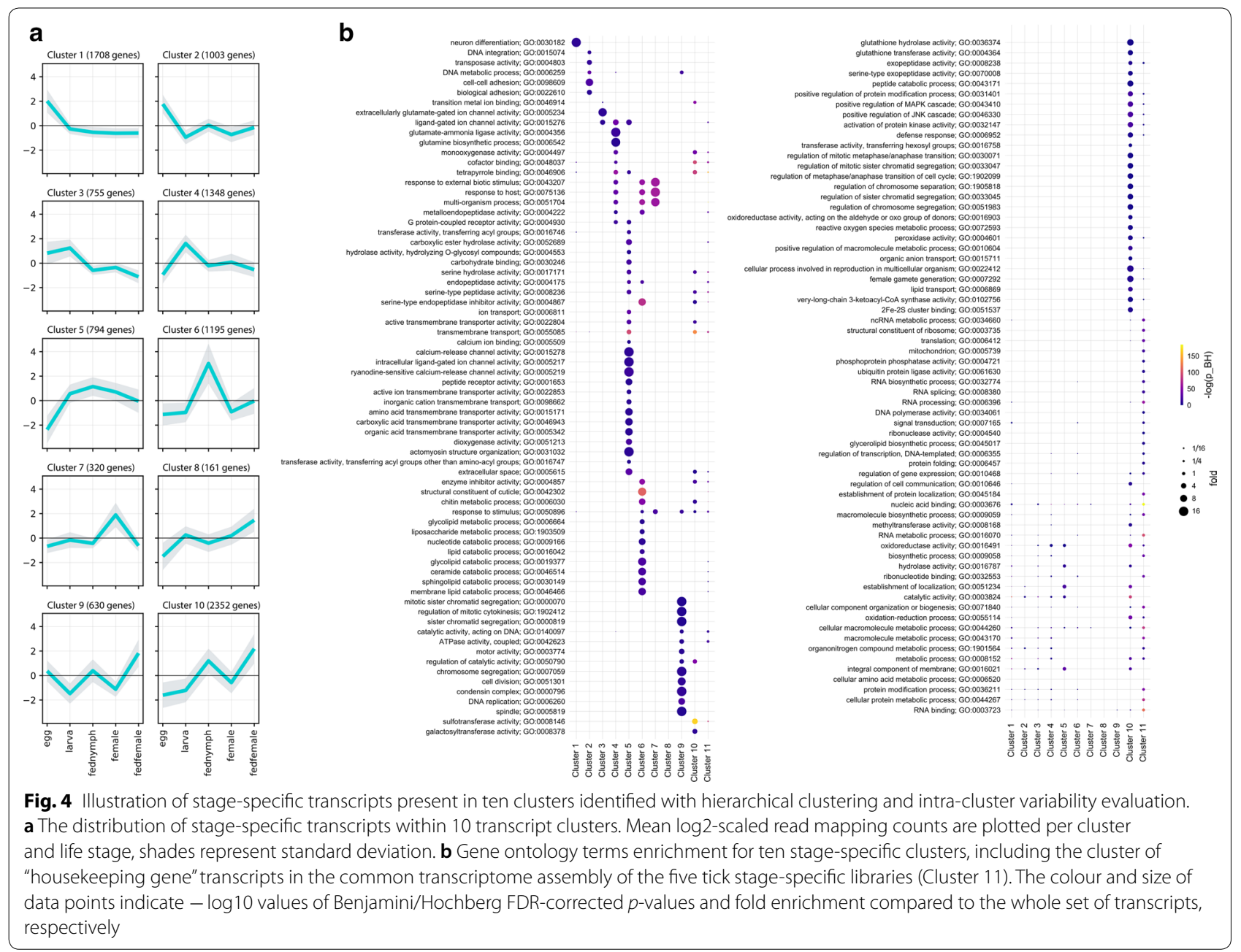

from the complement $\mathrm{C} 1 \mathrm{r} / \mathrm{C} 1 \mathrm{~s}$, Uegf, Bmp1), which is common for extracellular or cell membrane-associated proteins that are involved in developmentally regulated processes [66].

The Top 5 transcripts identified in larval transcriptome are related to salivary gland cement proteins as demonstrated by transcript c73350_g2 highly similar to loricrinlike protein (GenBank: XP_029826130.1) identified in $I$. scapularis $[67,68]$ and transcript sharing homology with cell wall components (c72525_g1 identical to GenBank: XP_029826132.1). The production of salivary gland related proteins in unfed stages implies an increased production of saliva, which is a typical physiological feature of questing unfed stages preparing for an upcoming blood meal especially after a prolonged period of starvation $[69,70]$.

\section{Fed nymph library-specific enrichment}

Transcripts in cluster 5 and 6 were identified in fed nymph transcriptome; Cluster 5 aggregates transcripts that are present in fed nymphs, larvae and females. The processes identified for transcripts in this cluster extend a wide range of functions, playing a role in very diverse cellular functions and may underlie processes that have later developmental onset but are neglected in a feeding female where most effort and resources are put into blood meal processing and primarily into reproduction. The most dominant GO terms in this cluster describe cellular signalization via ligand-dependent calcium channels, transmembrane transporter activities (e.g. GO:0015278, GO:005217, GO:005219) or metabolic processes (e.g. GO:0030246, GO:0004175, GO:0017171) involving lipidic molecules and by extent cell membrane structure and integrity (e.g. GO:0052689, GO:0016746), consistent with the observation in larvae (see below). Cluster 6 presents transcripts enriched in fed nymphs only. The most conspicuous activities associated with this cluster are involved in cuticle formation, catabolism of lipids, and enzymatic inhibition (e.g. GO:0042302, GO:0019377, GO:0004867). These activities are directly linked to tick feeding resulting in the fast growth of a tick 
cuticle-covered body which secures an efficient blood meal accommodation and also to blood digestion and its regulation, respectively. Additionally, the signalling pathways, responding to a foreign organism, are also activated in feeding nymphs (e.g. GO:0075136, GO:0043207).

\section{GO enrichment of unfed female}

Cluster 7 comprised transcripts enriched in unfed females. The GO terms typical for this cluster describe cofactor/tetrapyrrole binding activity (GO:0048037, GO:0046906) and signalling pathways triggered by external biotic stimuli or host (GO:0043207, GO: 0075136, GO:0051704).

The enrichment of these terms also occurred in larvae and fed nymphs, however, to a lower extent than in unfed females. Two of the Top 5 transcripts identified in the female library (c69267_g3 and c69267_g2) are homologous to salivary gland wc proteins identified previously in both $I$. ricinus and I. scapularis (GenBank: A0A0K8RIE7/AAZ66590.1 and A0A0K8RB73/ AAY66559.1, respectively).

\section{Fed female library-specific enrichment}

Transcript clusters 8 and 9 were specific for the fed female life stage. Interestingly, no enrichment occurred in cluster 8 , possibly as it is the smallest transcript cluster (161 contigs, i.e. $1.57 \%$ of transcripts assigned to different stage-specific libraries) and none of the class of transcripts was large enough to enable enrichment. Cluster 9 accommodates transcripts whose functions, as by enrichment, are nearly exclusively related to cell division processes including transcripts driving mitosis, DNA replication, chromatid segregation, etc. (e.g. GO:0007059, GO:0006260, GO:0005819).

\section{Feeding responsive transcript clusters}

Cluster 10 included transcripts that are typical for both, fed nymphs and fed females, and extends the widest range of GO terms of all ten transcript clusters. The most enriched terms describe processes which feeding stages utilize for blood meal processing and regulation, including protease activity, lipid processing and transport, also comprising lipid metabolism-related to cell wall integrity and composition (e.g. GO:0070008, GO:0036374, GO:0102756, GO:0006869). Blood-feeding is also associated with activities that are required for processing of toxic products of blood meal degradation (GO:0004601, GO:0072593) and for the elimination of foreign molecules and potentially pathogens incoming with the blood meal, thus inducing immune defence pathways (GO:0006952). Similarly to cluster 9, the transcripts associated with mitosis, cell division, and related processes are enriched (e.g. GO:0030071, GO:0033047,
GO:0033045). Also related are terms enriched for transcripts underlying factors regulating cell cycle (GO:0043410, GO:0046330). Another group of related GO terms describe transcripts influencing ovarian development, gametogenesis and reproduction (GO:0022412, GO:0007292). The Top 5 transcripts identified in both libraries of fed stages are mainly related to salivary glandrelated functions triggered during feeding and cuticle protein synthesis to support blood meal accommodation within the tick. For example, transcript c81210_g1 shows high similarity to the sequence (GenBank: Q9GP09) described in a study of salivary gland factors and their expression induced by blood meal in I. ricinus [71]. Further characterisation of this transcript showed its high sequence identity (over $80 \%$ ) with a glycine-rich protein identified in I. scapularis, related to fibroin heavy chain protein (GenBank: XP_029833024) involved in a buildup of cement which the tick uses for attachment of its hypostome to the host during feeding [68]. Similarly, the remaining annotated transcripts present in both libraries of feeding stages are of salivary gland origin or cuticlerelated. Additionally, fed females of haematophagous parasites typically highly expressed transcripts related to reproduction. This corresponds to the presence of transcripts homologous to vitellogenins (c79317_g2 identical to GenBank: EEC18889.1, and c80433_g1 identical to GenBank: A0A147BKD0), expressed in egg yolk, that were found among the Top 5 transcripts in the fed female library.

Also present in fed female transcriptome is a transcript homologous to lipocalin 1 , which is a protein typically produced in tick salivary glands and is a tick-specific evolutionary adaptation to blood-feeding [72].

The transcripts typical for both unfed larvae and females are mainly related to the processes involved in cell growth and cell cycle control or metabolism. An example is transcript c72929_g1 highly similar to the I. scapularis secreted protein (GenBank: EEC07345) of unknown identity whose homologous transcript GenBank: XP_029841102.1 underlies the production of a conserved cwc2 group pre-mRNA-splicing factor. Another two transcripts (c82554_g1 and c79150_g3, homologous to I. scapularis EEC03354 and EEC14461, respectively) of unknown function each contain an acyltransferase 3 family domain and an NRF superfamily domain (related GO term GO:0016747). The activity of proteins containing both these domains is usually associated with lipid metabolism, processing, or transport and could be, by extent, also related to cell membrane structure and integrity and cell membrane functional components, which was also observed in the model organism Caenorhabditis elegans [73, 74]. 


\section{Discussion}

\section{Feeding-responsive transcripts}

Four transcript clusters $(6,8,9$ and 10) recovered from our analysis are specific for fed stages of I. ricinus. Functional classification of most typical transcription was linked to cuticle formation and chitin metabolism as well as to the activation of blood-meal processing enzymes, all in response to a blood meal. These findings were anticipated and are in line with previous observations [30, 31, 33, 75].

Factors involved in mitosis and cell division are also commonly seen in feeding stages. Specific expression of these factors reflects the precocious cellular growth occurring shortly after a blood meal. Consistently, two GO terms (GO:0022412 and GO:0007292) involved in reproduction are enriched in both feeding stages. Their association with feeding females is fairly straightforward, underlying factors driving ovarian development and gamete generation. Enrichment of these transcripts in feeding nymphs is not self-evident; however, a lead to its functional elucidation in this non-adult stage can be found in thinly documented ecdysteroid hormonal regulation in ticks. The regulation of ecdysis is essential for the proper development of all arthropods, underlined by the existence of an organ dedicated to ecdysteroids production. In chelicerates, ecdysteroidogenesis and its regulation is poorly understood but possibly restricted to ovarian tissue in both its mature and immature life stages as in the soft tick Ornithodoros moubata [76]. This study suggests that factors driving reproduction, ovary development, and ecdysis might be tightly regulated. The involvement of tick nymphal ovary in processes decoupled from reproduction is demonstrated by its insensitivity to vitellogenin which plays a principal role in egg yolk formation and thus in gametogenesis and reproduction in arthropods $[77,78]$. Collectively, these findings along with an enrichment of reproductive transcripts in our fed nymph specific library strongly support the importance of ovary for ecdysteroidogenesis in ticks, thus corroborating the enrichment of reproduction-related transcripts in the feeding nymph. We suggest that transcripts functionally linked to reproduction in the library of fed nymphs are in fact involved in the development of ovary which clearly plays a role in the regulation of moulting in other ticks, and to the best of our knowledge, our findings are the first to describe this connection in I. ricinus tick.

\section{Transcripts identified in unfed stages}

The transcripts enriched in basic metabolic processes are present in larvae (glutamine-based metabolism; GO:0005234, GO:0004356, GO:0006542). Most of the related processes are also active in other life stages but their transcription is presumably overshadowed by processes more relevant for these stages. However, we suggest a linkage of some of these seemingly basic processes to specific functions in unfed tick stages. Perhaps, glutamate-ammonia ligase activity may point out GABAergic neuronal activity promoting larval motility [79]. Response to host or to external biotic stimuli was present in both females and larvae, though host-induced pathways were also observed for fed nymphs and thus might not be exclusive to unfed stages [80-83]. The presence of host response transcripts in larvae seems to be consistent with transcripts underlying glutamine metabolism of GABA-ergic neurons and host-seeking and was also observed in an unfed larva transcriptome library in other ticks [84].

Transcripts highly similar to I. scapularis secreted wc proteins were found prominent in unfed females (Table 4). This group of peptides, characterised by the presence of Trp-Cys dipeptide motif (thus "WC" proteins) at their $C$ termini, are apparently specific to ticks and their function is yet to be elucidated $[75,85,86]$.

\section{Transcription specific for egg development and tick embryogenesis}

Despite numerous efforts in basic and applied tick research [87-91], only one study has concentrated on the early stages of tick development [92]. A paucity of early-stage information hinders the implementation of targeted approaches, such as RNA interference or characterisation of vaccine candidates $[93,94]$. Our study is among the first to provide a comprehensive and biologically relevant catalogue of transcripts for future research aiming at controlling the population of ticks in the early stages of their development.

Apart from an anticipated functional enrichment in neuronal development (GO:0030182), observed in the embryonic development of other arthropods as well [95], cell adhesion-related transcripts (GO:0098609), clearly important for embryonic morphogenesis, were also highly enriched [96].

Of interest was an enrichment of factors unleashing mobile DNA transposition and consequent DNA integration which are typically reactivated during embryonic development. An elevated expression of transposase associated with transposon activity is usually less regulated in order to enable an implementation of developmental regulation of host DNA during embryogenesis [97]. Transposition-related activities can thus be considered markers of early tick embryonic development.

An increased expression of cathepsin protease observed in the egg library was also anticipated as cathepsin proteases take part in egg yolk proteolysis and thus are crucial for the energetic metabolism during embryogenesis $[65,94,98,99]$. Consistently, cathepsins have 
Table 4 Highest-ranking transcripts of the read mapping counts matrix in each of the five stage-specific assemblies

\begin{tabular}{|c|c|c|}
\hline Contig ID & Best blast hit & Description \\
\hline \multicolumn{3}{|l|}{ Egg } \\
\hline c77007_g1 & EEC13590.1 & Conserved hypothetical protein \\
\hline c80053_g1 & EEC03440.1 & Hypothetical protein IscW_ISCW003437 \\
\hline c80189_95 & A0A147BJ18 (IPR000859) & Putative conserved protein (CUB domain profile) \\
\hline C77756_g1 & EEC05138.1 & Unknown IscW_ISCW005232 \\
\hline C76180_g1 & EEC15123.1(GO:0006508; GO:0008234; IPR000169) & $\begin{array}{l}\text { Cathepsin-like protease (proteolysis; cysteine-type peptidase activity; } \\
\text { eukaryotic thiol (cysteine) proteases asparagine active site) }\end{array}$ \\
\hline \multicolumn{3}{|r|}{ 皮 } \\
\hline c73350_g2 & XP_029826130.1 (PR01217) & Loricrin-like (LOC115311581) (proline-rich extensin signature) \\
\hline C72525_g1 & XP_029826132.1 (PR01228) & $\begin{array}{l}\text { Glycine-rich cell wall structural protein 1.8-like (eggshell protein } \\
\text { signature) }\end{array}$ \\
\hline c82554_g1 & EEC03354.1 (GO:0016747; IPR002656) & $\begin{array}{l}\text { Conserved unknown (transferase activity, transferring acyl groups } \\
\text { other than amino-acyl groups; acyltransferase family) }\end{array}$ \\
\hline C72929_g1 & EEC07345.1 & Secreted protein \\
\hline c69133_g1 & EEC18324.1 & Secreted protein \\
\hline \multicolumn{3}{|l|}{ Fed nymph } \\
\hline c23277_g1 & JAA67414.1, A0A0K8RAB4 (PR01217) & Putative glycine rich protein (proline-rich extensin signature) \\
\hline c80070_g2 & V511 K9 & Putative salivary secreted protein of 21.3 kDa (fragment) \\
\hline c78019_g4 & EEC02888.1 (GO:0042302; IPR000618) & $\begin{array}{l}\text { Cuticle protein (structural constituent of cuticle; chitin-binding type } \\
\text { R\&R domain profile; insect cuticle protein) }\end{array}$ \\
\hline c81210_g1 & Q9GP09 & Unknown \\
\hline c75846_g6 & EEC18809.1 (PR01217) & Unknown IscW_ISCW023478 (proline-rich extensin signature) \\
\hline \multicolumn{3}{|l|}{ Female } \\
\hline c69267_g3 & A0A0K8RIE7 (AAY66590.1) & Putative wc protein, secreted protein \\
\hline c79150_g3 & EEC14461.1 & Unknown IscW_ISCW021550 \\
\hline C75091_g1 & EEC18324.1 & Secreted protein \\
\hline c69267_g2 & A0A0K8RB73 (AAY66559.1) & Putative wc protein, secreted salivary protein \\
\hline c1565_g1 & AAY66620.1, A0A0K8RG69 & Secreted protein \\
\hline \multicolumn{3}{|l|}{ Fed female } \\
\hline c79317_g2 & EEC18889.1 (GO:0005319; GO:0006869; IPR001747; IPR001846) & $\begin{array}{l}\text { Vitellogenin (lipid transporter activity; lipid transport; VWFD domain } \\
\text { profile; von Willebrand factor type D domain; vitellogenin domain } \\
\text { profile) }\end{array}$ \\
\hline c79647_g1 & EEC14155.1 (GO:0042302; IPR000618) & $\begin{array}{l}\text { Cuticle protein (structural constituent of cuticle; Chitin-binding type } \\
\text { R\&R domain profile; insect cuticle protein) }\end{array}$ \\
\hline C73798_g1 & V5I261 (GO:0030682; GO:0043176; IPR002970) & $\begin{array}{l}\text { Putative lipocal-1 } 1 \text { lipocalin (Fragment) (evasion or tolerance of host } \\
\text { defenses; amine binding; tick histamine binding protein) }\end{array}$ \\
\hline c80433_g1 & A0A147BKD0 (GO:0005319; GO:0006869; IPR001747; IPR001846) & $\begin{array}{l}\text { Putative vitellogenin } 2 \text { (Fragment) (lipid transporter activity; lipid } \\
\text { transport; VWFD domain profile; von Willebrand factor type D } \\
\text { domain; vitellogenin domain profile) }\end{array}$ \\
\hline C74644_g1 & A0A0K8RN13 (GO:0042302; IPR000618) & $\begin{array}{l}\text { Putative cuticle protein (fragment) (structural constituent of cuticle; } \\
\text { chitin-binding type R\&R domain profile; insect cuticle protein) }\end{array}$ \\
\hline
\end{tabular}

Notes: Accession numbers of the best blast hits and their description are supplied. GO term and/or IPS annotations including their respective descriptions are also listed when available

been in the scope as targets for tick control [100, 101]. CUB domain proteins were also found among egg-specific transcripts and their expression in an egg is most typically manifested in embryonic developmental factors [66]. CUB domains are found conserved in Metazoa and most often occur in cell surface proteins that mediate interactions of embryonal morphogenetic proteins and metalloproteases [102-104].

\section{Reference gene validation assay}

Reference gene validation using qRT-PCR is an essential step for proper quantitative data normalization. Currently, this is the most recognized methodology to provide reliable gene expression comparisons [105]. It is also a method of choice in cross-sample normalization of read count data or for the evaluation of normalization techniques in studies dealing with transcriptomic NGS data $[50,106,107]$. 
All genes tested in our study showed a high degree of stability among tick life stages as indicated by the correlation coefficient $(r)$. Still, it is crucial to carefully select candidate reference genes with respect to specific physiological circumstances given by the experimental design. Related to the tick development, specific examples can be found in haematophagous arthropods experiencing one or more blood meals in their life-cycle. This represents a radical alteration of physiological conditions and profoundly affects the expression of many genes, including those that are considered fairly stable in a majority of other organisms as is the case of $\beta$-actin in the kissing bug Rhodnius prolixus [108] or ribosomal components of Ae. aegypti during vitellogenesis triggered by a blood meal [109]. In our study, several ribosomal genes (RpL13A, RpL32, rpl4 and rps4) were tested and all of them proved highly stable. We ascribe such discordance to fundamental differences in the life-cycle among ticks and mosquitoes. In particular, the duration of bloodfeeding is substantially different, taking approximately two minutes in the mosquito in comparison to several days in the tick $[77,110]$, which certainly has implications to the initiation and progress of vitellogenesis [22, $76,111]$ and hence the expression stability of ribosomal genes. Accordingly, inspection of partially fed stages may have also contributed to ribosomal transcript stability in this work. Thus, the set of reference genes, rather than just one of them, can be applied in future studies comparing gene expression between tick life stages. However, the robustness of our reference gene set can lower under different study designs, for instance monitoring gene expression under specific experimental conditions, tissue-specific expression, or time-lapse expression in time points of tick development different than here, such as fully fed stages. We, therefore, highlight the importance of de novo validation of selected reference genes for specific experimental designs.

\section{Cataloguing a stage-specific transcription of Ixodes ricinus}

The main mission of our project was to produce a comprehensive catalogue of transcripts of the tick I. ricinus and identify transcripts specific for developmental stages of interest by their cross-stage comparison. Using entire bodies for sequencing was thus of importance. This approach allowed us to collect all transcripts that are typical of each life stage. The main limitation here is the risk of losing information about transcripts of very low abundance whose expression is either tissue-specific, or is restricted to a short period during development, or is induced by a specific physiological state. Sequencing of transcriptomes derived from individual tissues or time points, on the other hand, suffers from compositional bias which is manifested in the overrepresentation of functionally specific populations of transcripts, disregarding expression in other tissues or developmental periods. This is evident from the identification of transcripts exclusive for RNA libraries originating in different life stages of I. ricinus salivary glands [31].

In order to detect low-abundance transcripts, we performed sequencing of each library to a very high read depth using the HiSeq2000 Illumina platform. For each of our libraries, we received $72-120 \mathrm{M}$ of reads (PE50). Additionally, we prepared our transcriptome assembly from reads combined from all five stage-specific libraries. This approach should secure an even more comprehensive catalogue of transcripts representing the overall coding potential of the I. ricinus genome. Comparison of transcript number in our assembly $(25,872)$ with the coding capacity of $I$. scapularis $(23,340)$ [53], the closest relative species with publicly available genome data, also provided an indication about the high completeness of our assembly.

We additionally confirmed a good recovery of lowabundance transcripts in our assembly by searching for transcripts of genes whose expression was found to be tissue-specific and thus presumably very low in the population of all transcripts of the whole-body transcriptome. Based on previously published studies, we selected five genes whose expression had been found restricted to a specific tissue in the tick. Our BLAST search yielded $100 \%$ of query transcripts, which again validates the high completeness of our I. ricinus assembly. Evaluation of another tissue-specific marker, however, revealed that the sequence of the putative ixoderin B is 5' partial. Ixoderin $\mathrm{B}$ is a salivary gland-specific transcript in contrast to its A isoform which exhibits organism-wide transcription and whose corresponding transcript was fully assembled in our transcriptome. We admit limitations to our dataset in terms of both transcript presence and CDS completeness and encourage to inquire public databases to recover complete sequences of lowly expressed genes in the future. It is however very likely that the majority of low-abundance transcripts we removed from the raw assembly of 83,534 sequences are truncated sequences which do not represent biologically relevant transcription of the interrogated life stage. Our dataset thus constitutes a representative transcriptome of I. ricinus across life stages and the removal of truncated low-quality transcripts does not negatively influence an estimation of stage-specific transcription.

Our study was designed to cover the interpopulation expression variability of $I$. ricinus without losing the chance of recovery of lowly expressed transcripts or rare transcript isoforms underlying an interpopulation expression variability of this species. We thus pooled triplicated samples collected from ticks originating in 
different tick populations. This allowed us to produce a high per sample read coverage without compromising the full assembly of rare transcripts. This was done on the expense of reducing the reliability of transcriptome quality evaluation and general significance of conclusions that we derive from our sequencing project. However, with a series of quality filtering and evaluation tests as for example the BUSCO assessment, we were able to present a list of indicators supporting high efficiency of our bioinformatic approach and good quality of the output data. The same experimental design was also presented in previous publications where a single library per sample was sequenced on the expense of high sequence coverage [31, 33]. Using well-established bioinformatic pipelines along with a number of quality evaluation tests, the authors were able to construct reliable time- and tissue-dependent tick transcriptome assemblies supported by a single sequencing library per sample. This facilitated a postulation of firm conclusions based on well-organized analyses focused on the proper characterization of particular sample-specific assemblies, their reciprocal comparison, and an inference and functional annotation of sample-specific transcription.

With precaution, we performed de novo assembly instead of reference driven transcriptome reconstruction. Despite the existence of annotated reference genome of I. scapularis, a genome reference of related species may have obstructed assembly of $I$. ricinus sequences transcribed from highly interspecifically variable loci.

Our study was also organized to produce a representative catalogue of stage-specific transcripts that do not provide strong quantitative information about gene expression. Our transcriptome assembly was however submitted to a series of quality testing, normalization, and functional annotations. The bioinformatic pipeline that was eventually applied to our sequencing data was used upon thorough consultation of existing studies dealing with stage-specific transcription and with general bioinformatic guidelines [48, 50, 84, 107]. Due to a unique design of our study, we organized our work by a combination of different approaches based on assumptions derived from the type and nature of our data and, at the same time, from biological questions postulated in our project. The resulting outputs provided valuable information about processes and functions typical for each life stage. Moreover, our transcriptome database represents a priceless pool of information for initiation of future research projects that can be built upon the mere knowledge about transcription in I. ricinus followed by the associated validation of transcripts sequences and their cross-referencing with public databases. Moreover, the collection of transcripts specifically expressed in eggs can be exploited in the development of in vitro methods in tick-derived cell cultures originating in tick embryonic cells [38].

The descriptive nature of our study poses certain limits for an interpretation of our data in comparison with other quantitatively designed studies. On the other hand, putting our data into proper context, even within quantitative studies, can still present valid points for discussion with perspective for further confirmation by experimental approaches where required.

\section{Conclusions}

Our work presents and discusses new findings about developmentally specific transcripts identified in $I$. ricinus eggs, larvae, partially fed nymphs, females, and partially fed females. Proper normalization of our transcriptome assemblies was performed using a set of reference genes whose stability was verified by a quantitative gene validation essay of eleven candidate reference genes also presented in this study. Our data confirm the identity of transcripts involved in tick feeding presented in previous studies and support the role of ovary in ecdysteroidogenesis also in I. ricinus as was previously suggested in related tick species. Additionally, we describe processes and specific transcripts apparently important for embryogenesis, whereby most conspicuously energetic metabolism, developmental mobile DNA reactivation, and subsequent initiation of morphogenetic processes are crucial. Our study presents new insights into early and late tick development, consistent with previously published research and draws our findings into new biological contexts. As a whole, our work extends the collection of important information for further investigation in both basic and applied tick research, including the development of tick-targeted population control programs.

\section{Supplementary information}

Supplementary information accompanies this paper at https://doi. org/10.1186/s13071-020-04173-4.

Additional file 1: Table S1. Description of primers used in the housekeeping gene validation assay.

Additional file 2: Table S2. Summary of library mapping statistics and cross-sample normalization.

Additional file 3: Table S3. Summary of de novo assembly quality statistics.

Additional file 4: Alignment S1. Alignment of cathepsin D1 (GenBank: EF428204.1) query sequence and a corresponding transcript recovered from Ixodes ricinus stage-specific transcriptome assembly (c79321_g3_i1):: Alignment S1. Alignment of cathepsin D1 (GenBank: EF428204.1) query sequence and a corresponding transcript recovered from Ixodes ricinus stage-specific transcriptome assembly (c79321_g3_i1).

Additional file 5: Alignment S2. Alignment of cathepsin D2 (GenBank: HQ615697.1) query sequence and a corresponding transcript recovered from Ixodes ricinus stage-specific transcriptome assembly (c81800_g1_i2). 
Additional file 6: Alignment S3. Alignment of cathepsin D3 (GenBank: HQ615698.1) query sequence and a corresponding transcript recovered from Ixodes ricinus stage-specific transcriptome assembly (c81927_g1_i1).

Additional file 7: Alignment S4. Alignment of Iris (GenBank: AJ269658.2) query sequence and four corresponding transcripts representing Trinity assembler isoforms recovered from Ixodes ricinus stage-specific transcriptome assembly (c83951_g1_i2, c83951_g1_i5, c83951_g1_i3, c83951_g1_i1).

Additional file 8: Alignment S5. Alignment of ixoderin A (GenBank: AY341424.1) query sequence and a corresponding transcript recovered from Ixodes ricinus stage-specific transcriptome assembly (c80994_g1_i1).

Additional file 9: Alignment S6. Alignment of ixoderin B (GenBank: AY341424.1) query sequence and a truncated corresponding transcript recovered from Ixodes ricinus stage-specific transcriptome assembly (c82323_g13_i1).

Additional file 10: Table S4. List of stage-specific and housekeeping transcripts.

\section{Abbreviations}

cpm: counts per million; geoSTDEV: geometric standard deviation; GO: Gene Ontology; MED: median normalization; RLE: relative log expression; RSEM: RNA-seq by expectation-maximization; TBEV: tick-borne encephalitis virus; TMM: trimmed mean of M-values; TMMwsp: trimmed mean of M-values with singleton pairing; UQ: upper quartile.

\section{Acknowledgements}

We acknowledge computation resources provided by CERIT-SC and MetaCentrum, Brno, Czech Republic.

\section{Authors' contributions}

$P V$, JS and LG conceived the study. PV wrote the manuscript, organized the article, managed and produced tick samples used in this study, performed the reference gene validation assay and bioinformatic processing and evaluation of the tick transcriptomes. ZF supervised and corrected the manuscript and performed annotation and GO enrichment analysis of the transcriptomic data. JE is responsible for the tick rearing facility and provided all ticks used in this study. VB was in charge of library preparation and production of the sequencing data. PV and RC processed the sequencing data, including quality evaluation and assembly and mapping. All authors read and approved the final manuscript.

\section{Funding}

This study was supported by the Czech Science Foundation grants 18-27204S; by the Ministry of Education, Youth and Sports of the Czech Republic (projects LM2015055, LTARF 18021, and LTAUSA18040); and ERD Funds (the project CePaViP; CZ.02.1.01/0.0/0.0/16_019/0000759, Postdok_BIOGLOBE CZ.1.07/2.3.00/30.0032).

\section{Availability of data and materials}

All data generated or analysed during this study are included in this published article and its additional files. The Transcriptome Shotgun Assembly project has been deposited at DDBJ/EMBL/GenBank under the accession GIDG00000000. The version described in this paper is the first version, GIDG01000000.

\section{Ethics approval and consent to participate}

All animal experiments presented in this study were in accordance with the Animal Protection Law of the Czech Republic (\$17, Act No. 246/1992 Sb) and with the approval of the Czech Academy of Sciences (approval no. 161/2010).

\section{Consent for publication}

Not applicable.

\section{Competing interests}

The authors declare that they have no competing interests.

\section{Author details}

${ }^{1}$ Faculty of Science, University of South Bohemia, České Budějovice, Czech Republic. ${ }^{2}$ Biology Centre CAS, Institute of Parasitology, České Budějovice, Czech Republic. ${ }^{3}$ BIOCEV, Faculty of Science, Charles University, Prague, Czech Republic. ${ }^{4}$ Department of Plant Developmental Genetics, Institute of Biophysics of the Czech Academy of Sciences, Brno, Czech Republic. ${ }^{5}$ GeneCore, EMBL, Heidelberg, Germany.

Received: 7 January 2020 Accepted: 5 June 2020

Published online: 16 June 2020

\section{References}

1. Heyman P, Cochez C, Hofhuis A, Van Der Giessen J, Sprong H, Porter SR, et al. A clear and present danger: tick-borne diseases in Europe. Expert Rev Anti Infect Ther. 2010;8:33-50.

2. Michelet L, Delannoy S, Devillers E, Umhang G, Aspan A, Juremalm M, et al. High-throughput screening of tick-borne pathogens in Europe. Front Cell Infect Microbiol. 2014;4:103.

3. Vayssier-Taussat M, Kazimirova M, Hubalek Z, Hornok S, Farkas R, Cosson $\mathrm{JF}$, et al. Emerging horizons for tick-borne pathogens: From the "one pathogen-one disease" vision to the pathobiome paradigm. Future Microbiol. 2015:10:2033-43.

4. Honig V, Svec P, Halas P, Vavruskova Z, Tykalova H, Kilian P, et al. Ticks and tick-borne pathogens in South Bohemia (Czech Republic) - spatial variability in Ixodes ricinus abundance, Borrelia burgdorferi and tick-borne encephalitis virus prevalence. Ticks Tick Borne Dis. 2015;6:559-67.

5. Amicizia D, Domnich A, Panatto D, Lai PL, Cristina ML, Avio U, et al. Epidemiology of tick-borne encephalitis (TBE) in Europe and its prevention by available vaccines. Hum Vaccines Immunother. 2013:9:1 163-71.

6. Lindgren E, Jaenson, Thomas GT. Lyme borreliosis in Europe: influences of climate and climate change, epidemiology, ecology and adaptation measures. Copenhagen: WHO Regional Office for Europe Copenhagen; 2006.

7. Heinz FX, Stiasny K, Holzmann H, Grgic-Vitek M, Kriz B, Essl A, et al. Vaccination and tick-borne encephalitis, central Europe. Emerg Infect Dis. 2013;19:69-76.

8. Bogovic P. Tick-borne encephalitis: a review of epidemiology, clinical characteristics, and management. World J Clin Cases. 2015;3:430.

9. Steffen R. Epidemiology of tick-borne encephalitis (TBE) in international travellers to western/central Europe and conclusions on vaccination recommendations. J Travel Med. 2016;23:taw018.

10. van den Wijngaard CC, Hofhuis A, Simões M, Rood E, van Pelt W, Zeller $\mathrm{H}$, et al. Surveillance perspective on Lyme borreliosis across the European Union and European Economic Area. Euro Surveill. 2017:22:30569.

11. Sykes RA, Makiello P. An estimate of Lyme borreliosis incidence in western Europe. J Public Health (Oxf). 2017;39:74-81.

12. Cerny V. Sezónní dynamika klíštěte Ixodes risinus v divokém místě zaklištění. Československá Parazitol. 1957:4:57-8.

13. Roe RM, Donohue KV, Khalil SMS, Sonenshine DE. Hormonal regulation of metamorphosis and reproduction in ticks. Front Biosci. 2008:13:7250-68.

14. Sonenshine DE, Roe RM, editors. Biology of Ticks, vol. 1, 2nd edn. New York: Oxford University Press (OUP); 2014

15. Walker AR. Review of "Ticks: biology, disease and control" by Alan Bowman \& Patricia Nuttall (eds.). Parasit Vectors. 2009;2:1.

16. Foldvari G. Life cycle and ecology of Ixodes ricinus: the roots of public health importance. In: Braks MAH, Van Wieren SE, Takken W, Sprong $\mathrm{H}$, editors. Ecology and prevention of Lyme borreliosis. Ecology and control of vector-borne diseases, vol. 4. Wageningen: Wageningen Academic Publishers; 2016. p. 31-40.

17. Balashov YS. Ixodid ticks: parasites and vectors of infections. St. Petersburg: Nauka; 1998.

18. Balashov YS. Bloodsucking ticks (Ixodoidea) - vectors of disease in man and animals. Misc Publ Entomol Soc Am. 1972;8:163-376.

19. Honzakova E, Olejnicek J, Cerny V, Daniel M, Dusbabek F. Relationship between number of eggs deposited and body weight of engorged Ixodes ricinus female. Folia Parasitol. 1975;22:37-42. 
20. Gray JS, Kahl O, Lane RS, Levin ML, Tsao Jl. Diapause in ticks of the medically important Ixodes ricinus species complex. Ticks Tick Borne Dis. 2016;7:992-1003.

21. Dana AN, Hong YS, Kern MK, Hillenmeyer ME, Harker BW, Lobo NF, et al. Gene expression patterns associated with blood-feeding in the malaria mosquito Anopheles gambiae. BMC Genomics. 2005;6:5

22. Reid WR, Zhang L, Liu N. Temporal gene expression profiles of pre blood-fed adult females immediately following eclosion in the southern house mosquito Culex quinquefasciatus. Int J Biol Sci. 2015;11:1306-13.

23. Thangamani S, Wikel SK. Differential expression of Aedes aegypti salivary transcriptome upon blood feeding. Parasit Vectors. 2009;2:34.

24. Karim S, Singh P, Ribeiro JMC. A deep insight into the sialotranscriptome of the gulf coast tick. Amblyomma maculatum. PLoS One. 2011;6:e28525.

25. Schwarz A, Medrano-Mercado N, Schaub GA, Struchiner CJ, Bargues $M D$, Levy MZ, et al. An updated insight into the sialotranscriptome of Triatoma infestans: developmental stage and geographic variations. PLoS Negl Trop Dis. 2014;8:e3372.

26. Bensaoud C, Nishiyama MY, Ben Hamda C, Lichtenstein F, Castro De Oliveira U, Faria F, et al. De novo assembly and annotation of Hyalomma dromedarii tick (Acari: Ixodidae) sialotranscriptome with regard to gender differences in gene expression. Parasit Vectors. 2018;11:314.

27. Perner J, Provaznik J, Schrenkova J, Urbanova V, Ribeiro JMC, Kopacek P. RNA-seq analyses of the midgut from blood- and serum-fed Ixodes ricinus ticks. Sci Rep. 2016;6:36695.

28. Santiago PB, De Araújo CN, Motta FN, Praça YR, Charneau S, Bastos IMD, et al. Proteases of haematophagous arthropod vectors are involved in blood-feeding, yolk formation and immunity - a review. Parasit Vectors. 2017;10:79.

29. Kotsyfakis M, Kopáček P, Franta Z, Pedra JHF, Ribeiro JMC. Deep sequencing analysis of the Ixodes ricinus haemocytome. PLoS Negl Trop Dis. 2015;9:e0003754.

30. Charrier NP, Couton M, Voordouw MJ, Rais O, Durand-Hermouet A Hervet $C$, et al. Whole body transcriptomes and new insights into the biology of the tick Ixodes ricinus. Parasit Vectors. 11:364.

31. Schwarz A, Von Reumont BM, Erhart J, Chagas AC, Ribeiro JMC, Kotsyfakis M. De novo Ixodes ricinus salivary gland transcriptome analysis using two next-generation sequencing methodologies. FASEB J. 2013;27:4745-56.

32. Schwarz A, Tenzer S, Hackenberg M, Erhart J, Gerhold-Ay A, Mazur J, et al. A systems level analysis reveals transcriptomic and proteomic complexity in /xodes ricinus midgut and salivary glands during early attachment and feeding. Mol Cell Proteomics. 2014;13:2725-35.

33. Kotsyfakis M, Schwarz A, Erhart J, Ribeiro JMC. Tissue- and timedependent transcription in Ixodes ricinus salivary glands and midguts when blood feeding on the vertebrate host. Sci Rep. 2015;5:9103.

34. Mans BJ, Andersen JF, Francischetti IMB, Valenzuela JG, Schwan TG, Pham VM, et al. Comparative sialomics between hard and soft ticks: implications for the evolution of blood-feeding behavior. Insect Biochem Mol Biol. 2008;38:42-58.

35. Esteves E, Maruyama SR, Kawahara R, Fujita A, Martins LA, Righi AA, et al. Analysis of the salivary gland transcriptome of unfed and partially fed Amblyomma sculptum ticks and descriptive proteome of the saliva. Front Cell Infect Microbiol. 2017:7:476.

36. Landulfo GA, Patané JSL, da Silva DGN, Junqueira-de-Azevedo ILM, Mendonca RZ, Simons SM, et al. Gut transcriptome analysis on females of Ornithodoros mimon (Acari: Argasidae) and phylogenetic inference of ticks. Rev Bras Parasitol Vet. 2017;26:185-204.

37. Araujo RN, Silva NCS, Mendes-Sousa A, Paim R, Costa GCA, Dias LR, et al. RNA-seq analysis of the salivary glands and midgut of the Argasid tick Ornithodoros rostratus. Sci Rep. 2019;9:6764

38. Bell-Sakyi L, Zweygarth E, Blouin EF, Gould EA, Jongejan F. Tick cell lines: tools for tick and tick-borne disease research. Trends Parasitol. 2007;23:450-7.

39. Bolger AM, Lohse M, Usadel B. Trimmomatic: A flexible trimmer for Illumina Sequence Data. Bioinformatics. 2014;30:2114-20.

40. Haas BJ, Papanicolaou A, Yassour M, Grabherr M, Blood PD, Bowden J, et al. De novo transcript sequence reconstruction from RNA-seq using the Trinity platform for reference generation and analysis. Nat Protoc. 2013:8:1494-512.
41. Li H, Handsaker B, Wysoker A, Fennell T, Ruan J, Homer N, et al. The sequence alignment/map format and SAMtools. Bioinformatics. 2009;25:2078-9.

42. Simao FA, Waterhouse RM, loannidis P, Kriventseva EV, Zdobnov EM BUSCO: assessing genome assembly and annotation completeness with single-copy orthologs. Bioinformatics. 2015;31:3210-2.

43. Laetsch DR, Blaxter ML. BlobTools: interrogation of genome assemblies [version 1; peer review: 2 approved with reservations]. F1000Research. 2017;6:1287.

44. Jones P, Binns D, Chang HY, Fraser M, Li W, McAnulla C, et al. InterProScan 5: genome-scale protein function classification. Bioinformatics. 2014;30:1236-40.

45. Rozewicki J, Li S, Amada KM, Standley DM, Katoh K. MAFFT-DASH: integrated protein sequence and structural alignment. Nucleic Acids Res. 2019;47:W5-10.

46. Glaser RW. "Ringer" solutions and some notes on the physiological basis of their ionic composition. Comp Biochem Physiol. 1917;2:241-89.

47. Pfaffl MW, Tichopad A, Prgomet C, Neuvians TP. Determination of stable housekeeping genes, differentially regulated target genes and sample integrity: BestKeeper - Excel-based tool using pair-wise correlations. Biotechnol Lett. 2004;26:509-15.

48. Vandesompele J, De Preter K, Pattyn F, Poppe B, Van Roy N, De Paepe A, et al. Accurate normalization of real-time quantitative RT-PCR data by geometric averaging of multiple internal control genes. Genome Biol. 2002;3(research0034):1.

49. Li B, Dewey CN. RSEM: accurate transcript quantification from RNA-Seq data with or without a reference genome. BMC Bioinf. 2011;12:323.

50. Evans C, Hardin J, Stoebel DM. Selecting between-sample RNA-Seq normalization methods from the perspective of their assumptions. Brief Bioinform. 2018;19:776-92.

51. Maza E, Frasse P, Senin P, Bouzayen M, Zouine M. Comparison of normalization methods for differential gene expression analysis in RNA-seq experiments: a matter of relative size of studied transcriptomes. Commun Integr Biol. 2013;6:e25849.

52. Klopfenstein DV, Zhang L, Pedersen BS, Ramírez F, Vesztrocy AW, Nald A, et al. GOATOOLS: a python library for gene ontology analyses. Sci Rep. 2018;8:10872.

53. Pagel Van Zee J, Geraci NS, Guerrero FD, Wikel SK, Stuart JJ, Nene VM, et al. Tick genomics: the Ixodes genome project and beyond. Int J Parasitol. 2007;37:1297-305.

54. Sojka D, Franta Z, Frantová H, Bartošová P, Horn M, Váchová J, et al. Characterization of gut-associated cathepsin D hemoglobinase from tick Ixodes ricinus (IrCD1). J Biol Chem. 2012;287:21152-63.

55. Leboulle G, Crippa M, Decrem Y, Mejri N, Brossard M, Bollen A, et al. Characterization of a novel salivary immunosuppressive protein from Ixodes ricinus ticks. J Biol Chem. 2002;277:10083-9.

56. Rego ROM, Hajdusek O, Kovar V, Kopacek P, Grubhoffer L, Hypsa V Molecular cloning and comparative analysis of fibrinogen-related proteins from the soft tick Ornithodoros moubata and the hard tick Ixodes ricinus. Insect Biochem Mol Biol. 2005;35:991-1004.

57. Yang C, Pan H, Liu Y, Zhou X. Stably expressed housekeeping genes across developmental stages in the two-spotted spider mite, Tetranychus urticae. PLoS One. 2015;10:e0120833.

58. Nijhof AM, Balk JA, Postigo M, Jongejan F. Selection of reference genes for quantitative RT-PCR studies in Rhipicephalus (Boophilus) microplus and Rhipicephalus appendiculatus ticks and determination of the expression profile of Bm86. BMC Mol Biol. 2009;10:112.

59. Koci J, Simo L, Park Y. Validation of internal reference genes for real-time quantitative polymerase chain reaction studies in the tick, Ixodes scapularis (Acari: Ixodidae). J Med Entomol. 2013;50:79-84.

60. Bionaz M, Loor JJ. Identification of reference genes for quantitative real-time PCR in the bovine mammary gland during the lactation cycle. Physiol Genomics. 2007;29:312-9.

61. Kaur R, Sodhi M, Sharma A, Sharma VL, Verma P, Swami SK, et al. Selection of suitable reference genes for normalization of quantitative RT-PCR (RT-qPCR) expression data across twelve tissues of riverine buffaloes (Bubalus bubalis). PLoS One. 2018;13:e0191558.

62. Razavi SA, Afsharpad M, Modarressi MH, Zarkesh M, Yaghmaei P, Nasiri S, et al. Validation of reference genes for normalization of relative qRT-PCR studies in papillary thyroid carcinoma. Sci Rep. 2019;9:15241. 
63. Caracausi M, Piovesan A, Antonaros F, Strippoli P, Vitale L, Pelleri MC. Systematic identification of human housekeeping genes possibly useful as references in gene expression studies. Mol Med Rep. 2017;16:2397-410.

64. Chim SSC, Wong KKW, Chung CYL, Lam SKW, Kwok JSL, Lai CY, et al. Systematic selection of reference genes for the normalization of circulating RNA transcripts in pregnant women based on RNA-Seq data. Int J Mol Sci. 2017;18:E1709.

65. Sojka D, Francischetti IMB, Calvo E, Kotsyfakis M. Cysteine proteases from bloodfeeding arthropod ectoparasites. Adv Exp Med Biol. 2011;712:177-91.

66. Bork P, Beckmann G. The CUB domain: a widespread module in developmentally regulated proteins. J Mol Biol. 1993;231:539-45.

67. Francischetti IMB, Sa-Nunes A, Mans BJ, Santos IM, Ribeiro JMC. The role of saliva in tick feeding. Front Biosci. 2009;14:2051-88.

68. Suppan J, Engel B, Marchetti-Deschmann M, Nürnberger S. Tick attachment cement-reviewing the mysteries of a biological skin plug system. Biol Rev. 2018;93:1056-76.

69. Tirloni L, Kim TK, Berger M, Termignoni C, da Silva Vaz I, Mulenga A Amblyomma americanum serpin 27 (AAS27) is a tick salivary anti-inflammatory protein secreted into the host during feeding. PLoS Negl Trop Dis. 2019;13:e0007660.

70. Rosendale AJ, Dunlevy ME, McCue MD, Benoit JB. Progressive behavioural, physiological and transcriptomic shifts over the course of prolonged starvation in ticks. Mol Ecol. 2019;28:49-65.

71. Leboulle G, Rochez C, Louahed J, Rutti B, Brossard M, Bollen A, et al. Isolation of Ixodes ricinus salivary gland mRNA encoding factors induced during blood feeding. Am J Trop Med Hyg. 2002;66:225-33.

72. Ganfornina MD, Kayser H, Sanchez D. Lipocalins in Arthropoda: diversification and functional explorations. In: Akerstrom B, Borregaard N, Flower DR, Salier JP, editors. Lipocalins. Austin: Landes Bioscience; 2006. p. 49-74.

73. Choy R, Thomas JH. Fluoxetine-resistant mutants in C. elegans define a novel family of transmembrane proteins. Mol Cell. 1999:4:143-52.

74. Choy RKM, Kemner JM, Thomas JH. Fluoxetine-resistance genes in Caenorhabditis elegans function in the intestine and may act in drug transport. Genetics. 2006;172:885-92.

75. Chmelar J, Anderson JM, Mu J, Jochim RC, Valenzuela JG, Kopecky J. Insight into the sialome of the castor bean tick, Ixodes ricinus. BMC Genomics. 2008;9:233

76. Ogihara MH, Hikiba J, Suzuki Y, Taylor DM, Kataoka H. Ovarian ecdysteroidogenesis in both immature and mature stages of an acari, Ornithodoros moubata. PLoS One. 2015:10:e0124953.

77. Richards MH. Vitellogenin and vitellogenin-like genes: not just for egg production. Insects Soc. 2019;66:505-6.

78. Taylor D, Chinzei Y, Ito K, Higuchi N, Ando K. Stimulation of vitellogenesis by pyrethroids in mated and virgin female adults, male adults, and fourth instar females of Ornithodoros moubata (Acari: Argasidae). J Med Entomol. 1991;28:322-9.

79. Lumaret JP, Errouissi F, Floate K, Rombke J, Wardhaugh K. A review on the toxicity and non-target effects of macrocyclic lactones in terrestrial and aquatic environments. Curr Pharm Biotechnol. 2012;13:1004-60.

80. Hodzic E, Fish D, Maretzki CM, De Silva AM, Feng S, Barthold SW. Acquisition and transmission of the agent of human granulocytic ehrlichiosis by Ixodes scapularis ticks. J Clin Microbiol. 1998;36:3574-8.

81. Kocan KM, de la Fuente J, Coburn LA. Insights into the development of Ixodes scapularis: a resource for research on a medically important tick species. Parasit Vectors. 2015;8:592

82. Scott JD, Clark KL, Coble NM, Ballantyne TR. Detection and transstadial passage of Babesia species and Borrelia burgdorferi sensu lato in ticks collected from avian and mammalian hosts in Canada. Healthcare. 2019;7:155.

83. Liu XY, Bonnet SI. Hard tick factors implicated in pathogen transmission PLoS Negl Trop Dis. 2014;8:e2566.

84. Villar M, Popara M, Ayllón N, De Fernández Mera IG, Mateos-Hernández $L$, Galindo RC, et al. A systems biology approach to the characterization of stress response in Dermacentor reticulatus tick unfed larvae. PLoS One. 2014;9:e89564

85. Ribeiro JMC, Alarcon-Chaidez F, Ivo IM, Mans BJ, Mather TN, Valenzuela $J G$, et al. An annotated catalog of salivary gland transcripts from Ixodes scapularis ticks. Insect Biochem Mol Biol. 2006:36:111-29.
86. Kim YH, Islam MS, You MJ. Proteomic screening of antigenic proteins from the hard tick, Haemaphysalis longicornis (Acari: Ixodidae). Korean J Parasitol. 2015:53:85-93.

87. Nuttall PA, Trimnell AR, Kazimirova M, Labuda M. Exposed and concealed antigens as vaccine targets for controlling ticks and tick-borne diseases. Parasite Immunol. 2006;28:155-63.

88. Labuda M, Trimnell AR, Ličková M, Kazimírová M, Davies GM, Lissina $O$, et al. An antivector vaccine protects against a lethal vector-borne pathogen. PLoS Pathog. 2006;2:e27.

89. Merino O, Alberdi P, Pérez De La Lastra JM, de la Fuente J. Tick vaccines and the control of tick-borne pathogens. Front Cell Infect Microbiol. 2013;3:30.

90. Sprong H, Trentelman J, Seemann I, Grubhoffer L, Rego ROM, Hajdušek $\mathrm{O}$, et al. ANTIDotE: anti-tick vaccines to prevent tick-borne diseases in Europe. Parasit Vectors. 2014;7:77.

91. Rego ROM, Trentelman JJA, Anguita J, Nijhof AM, Sprong H, Klempa $B$, et al. Counterattacking the tick bite: towards a rational design of anti-tick vaccines targeting pathogen transmission. Parasit Vectors. 2019;12:229.

92. Santos VT, Ribeiro L, Fraga A, de Barros CM, Campos E, Moraes J, et al. The embryogenesis of the tick Rhipicephalus (Boophilus) microplus: the establishment of a new chelicerate model system. Genesis. 2013:51:803-18

93. Seixas A, Oliveira P, Termignoni C, Logullo C, Masuda A, da Silva Vaz I. Rhipicephalus (Boophilus) microplus embryo proteins as target for tick vaccine. Vet Immunol Immunopathol. 2012;148:149-56.

94. Hussein HE, Johnson WC, Taus NS, Suarez CE, Scoles GA, Ueti MW. Silencing expression of the Rhipicephalus microplus vitellogenin receptor gene blocks Babesia bovis transmission and interferes with oocyte maturation. Parasit Vectors. 2019;12:7.

95. Artieri CG, Fraser HB. Transcript length mediates developmental timing of gene expression across drosophila. Mol Biol Evol. 2014;31:2879-89.

96. Shawky JH, Davidson LA. Tissue mechanics and adhesion during embryo development. Dev Biol. 2015;401:152-64.

97. Bourque G, Burns KH, Gehring M, Gorbunova V, Seluanov A, Hammell $M$, et al. Ten things you should know about transposable elements. Genome Biol. 2018;19:199.

98. Estrela A, Seixas A, Termignoni C. A cysteine endopeptidase from tick (Rhipicephalus (Boophilus) microplus) larvae with vitellin digestion activity. Comp Biochem Physiol B Biochem Mol Biol. 2007;148:410-6.

99. Zhang TT, Qiu ZX, Li Y, Wang WY, Li MM, Guo P, et al. The mRNA expression and enzymatic activity of three enzymes during embryonic development of the hard tick Haemaphysalis longicornis. Parasit Vectors. 2019;12:96.

100. Seixas A, Leal AT, Nascimento-Silva MCL, Masuda A, Termignoni C, da Silva Vaz I. Vaccine potential of a tick vitellin-degrading enzyme (VTDCE). Vet Immunol Immunopathol. 2008:124:332-40.

101. Martins R, Ruiz N, Fonseca RN da, Vaz Junior I da S, Logullo C. The dynamics of energy metabolism in the tick embryo. Rev Bras Parasitol Vet. 2018;27:259-66.

102. Song JL, Wong JL, Wessel GM. Oogenesis: single cell development and differentiation. Dev Biol. 2006;300:385-405.

103. Lee HX, Mendes FA, Plouhinec JL, De Robertis EM. Enzymatic regulation of pattern: BMP4 binds CUB domains of tolloids and inhibits proteinase activity. Genes Dev. 2009;23:2551-62.

104. Nunes da Fonseca R, van der Zee M, Roth S. Evolution of extracellular Dpp modulators in insects: the roles of tolloid and twisted-gastrulation in dorsoventral patterning of the Tribolium embryo. Dev Biol. 2010;345:80-93.

105. Radonić A, Thulke S, Mackay IM, Landt O, Siegert W, Nitsche A. Guideline to reference gene selection for quantitative real-time PCR. Biochem Biophys Res Commun. 2004;313:856-62.

106. Zyprych-Walczak J, Szabelska A, Handschuh L, Górczak K, Klamecka K, Figlerowicz $M$, et al. The impact of normalization methods on RNA-Seq data analysis. Biomed Res Int. 2015;2015:621690.

107. Wang Z, Lyu Z, Pan L, Zeng G, Randhawa P. Defining housekeeping genes suitable for RNA-seq analysis of the human allograft kidney biopsy tissue. BMC Med Genomics. 2019;12:86.

108. Paim RM, Pereira MH, Di Ponzio R, Rodrigues JO, Guarneri AA, Gontijo $N F$, et al. Validation of reference genes for expression analysis in the salivary gland and the intestine of Rhodnius prolixus (Hemiptera, 
Reduviidae) under different experimental conditions by quantitative real-time PCR. BMC Res Notes. 2012;5:128.

109. Niu LL, Fallon AM. Differential regulation of ribosomal protein gene expression in Aedes aegypti mosquitoes before and after the blood meal. Insect Mol Biol. 2000;9:613-23.

110. Chadee DD, Beier JC, Mohammed RT. Fast and slow blood-feeding durations of Aedes aegypti mosquitoes in Trinidad. J Vector Ecol. 2002;27:172-7.

111. Valzania L, Mattee MT, Strand MR, Brown MR. Blood feeding activates the vitellogenic stage of oogenesis in the mosquito Aedes aegypti through inhibition of glycogen synthase kinase 3 by the insulin and TOR pathways. Dev Biol. 2019;454:85-95.
112. Hajdusek O, Almazán C, Loosova G, Villar M, Canales M, Grubhoffer L, et al. Characterization of ferritin 2 for the control of tick infestations. Vaccine. 2010;28:2993-8.

\section{Publisher's Note}

Springer Nature remains neutral with regard to jurisdictional claims in published maps and institutional affiliations.
Ready to submit your research? Choose BMC and benefit from:

- fast, convenient online submission

- thorough peer review by experienced researchers in your field

- rapid publication on acceptance

- support for research data, including large and complex data types

- gold Open Access which fosters wider collaboration and increased citations

- maximum visibility for your research: over $100 \mathrm{M}$ website views per year

At BMC, research is always in progress.

Learn more biomedcentral.com/submissions 